\title{
MODERNISASI PEMBELAJARAN BAHASA ARAB DI DAYAH MUDI MESRA SAMALANGA KABUPATEN BIREUEN
}

\author{
Fauzan \\ Sekolah Tinggi Agama Islam (STAI) Jamiatut Tarbiyah Lhoksukon \\ Jln. Nga Matang Ubi, Lhoksukon, Kabupaten Aceh Utara, Aceh 24386 \\ Email:fznsyarifuddin@yahoo.com
}

\begin{tabular}{|l|l|l|}
\hline Diterima:03 April 2017 & Revisi:05 Mei 2017 & Disetujui: 6 Juni 2017 \\
\hline
\end{tabular}

\begin{abstract}
This article discusses the modernization of Arabic learning in Dayah MUDI Mesra, Samalanga Bireuen District. The attention and study of the teaching of Arabic is still important even in the pesantren. Because, but it is possible that the learning still needs improvement, considering that many pesantren are less concerned about the methods and the learning curriculum, whereas both are important aspects in the development of learning. This study is a research field of evaluation of education, by studying the teaching practice of the field of Arabic language study in Dayah MUDI Mesra Samalangan Bireuen District.
\end{abstract}

Keywords: modernization, arabic learning, learning curriculum

\begin{abstract}
Abstrak
Artikel ini membahas tentang modernisasi pembelajaran bahasa arab di Dayah MUDI Mesra, Samalanga Kabupaten Bireuen. Perhatian dan telaah terhadap pengajaran bahasa Arab tersebut tetap penting dilakukan sekalipun di pesantren. Sebab, tapi tidak tertutup kemungkinan bahwa pembelajarannya masih memerlukan perbaikan, mengingat banyak pesantren yang kurang peduli terhadap metode dan kurikulum pembelajaran, padahal keduanya merupakan aspek penting dalam pengembangan pembelajaran. Penelitian ini merupakan penelitian bidang kajian evaluasi pendidikan, dengan mengkaji
\end{abstract}


praktek pengajaran bidang studi bahasa Arab yang di Dayah MUDI Mesra Samalangan Kabupaten Bireuen.

Kata Kunci: Modernisasi, pembelajaran arab, kurikulum pembelajaran

\section{A. Pendahuluan}

Jika berbicara dalam konteks Indonesia, maka sejauh ini belum ada hasil penelitian yang memastikan sejak kapan pengajaran bahasa Arab mulai dirintis dan dikembangkan. Asumsi yang selama ini berkembang adalah bahwa bahasa Arab sudah mulai dikenal oleh bangsa Indonesia sejak Islam dikenal dan dianut oleh mayoritas bangsa kita. Jika Islam secara meluas telah dianut oleh masyarakat kita pada abad ke-13, maka usia pendidikan bahasa Arab dipastikan sudah lebih dari 7 abad. Dengan demikian, bahasa Arab di Indonesia jauh lebih "tua dan senior" dibandingkan dengan bahasa asing lainnya, seperti: Belanda, Inggris, Portugal, Mandarin, dan Jepang.

Pendidikan bahasa Arab di Indonesia kini sudah diajarkan mulai dari tingkat pendidikan dasar hingga perguruan tinggi baik melalui pendidikan formal maupun non formal. Berbagai potret penyelenggaraan pendidikan bahasa Arab di lembaga-lembaga pendidikan Islam setidaknya menunjukkan adanya upaya serius untuk memajukan sistem dan mutunya. Namun demikian, bahasa Arab di Indonesia sepertinya masih dianggap secara eksklusif sebagai bahasa Islam. Sehingga, pengajaran bahasa Arab yang memiliki keunggulan dalam metode pembelajarannya menjadi sangat identik dengan lembaga pendidikan Islam itu sendiri, yakni pesantren dan beberapa jenis lembaga pendidikan Islam yang tumbuh berkembang seiring dengan perkembangan Islam ditanah air dari awal masuknya Islam hingga sampai pada abad ini.

Dalam pesantren, pembelajaran bahasa Arab dibedakan dalam dua kelompok metode pengajaran, yaitu pembelajaran berbasis metode tradisional dan metode modern sebagaimana pesantren juga kerap dikelompokkan ke dalam dua kategori tersebut. Pesantren menganggap bahwa bahasa Arab merupakan salah satu dari sekian banyak materi dalam pendidikan keagamaan, 
sehingga mereka merasa harus mempelajarinya. Selain itu, bahwa dalam fase perkembangannya bahasa Arab sendiri telah dijadikan sebagai bahasa internasional disamping bahasa Inggris, ini tentunya menjadi semangat tambahan bagi pesantren untuk mengajarkannya.

Bahasa Arab dalam posisinya yang demikian penting, menjadi sangat urgen untuk ditelaah kembali guna memperoleh kemudahan dalam proses pembelajaran secara efektif dan efesien. Sebab tanpa telaah ulang, barangkali persoalan-persoalan yang muncul tidak dapat teridentifikasi. Dalam realitas lain, bisa jadi pembelajaran bahasa Arab menjadi hal yang kurang diperhatikan, semangat pembelajarpun semakin rendah, serta programprogram pengajarannya kurang berkembang dan kurang mencapai taraf dan tujuan pembelajaran. Dengan demikian, maka tidaklah berlebihan rasanya bila pengajaran bahasa Arab perlu mendapatkan perhatian dan pengembangan yang lebih luas terutama sekali metode pengajarannya yang lebih modern agar lebih mudah diterima oleh peserta didik kemudian dipahami untuk digunakannya dalam kehidupan.

Contoh persoalan dalam pengajaran bahasa Arab adalah seperti yang disinyalir oleh Zaenuddin, bahwa metode pengajaran bahasa Arab yang banyak berkembang terutama pada lembaga-lembaga pendidikan formal seperti Madrasah lebih menitikberatkan pada penguasaan qawaid (tata bahasa) atau Grammar Translation Method. ${ }^{1}$ Jika demikian adanya, maka hal tersebut tentu memiliki dampak tersendiri bagi peserta didik dalam mempelajari bahasa Arab terutama bagi tingkat pemula. Bagi mereka, qawaid (tata bahasa), Nahu/ Sharaf, dan ilmu tata bahasa Arab lainnya akan terasa menyulitkan karena membutuhkan waktu yang sangat lama untuk menghafal sejumlah qawaid (tata bahasa). ${ }^{2}$ Secara psikologis, kondisi tersebut berpotensi memunculkan kebosanan atau berkurangnya daya tarik bahasa Arab bagi siswa, yang pada akhirnya juga tidak menguntungkan bagi yang mengajarkan bahasa Arab

1 Radliyah Zaenuddin, Metodologi Dan Strategi Alternatif Pembelajaran Bahasa Arab, (Yogyakarta: Pustaka Rihlah Group, 2005), h. 3.

2 Thayar Yusuf and Syaiful Anwar, Metode Pengajaran Agama Dan Bahasa Arab, (Jakarta: Raja Grafindo Persada, 1994), h. 189. 
karena prinsip mengajar bahasa Arab bertujuan agar anak didik menyukai dan mau berbahasa Arab, sehingga menganggap bahasa Arab menjadi bahagian terpenting dari bahasa mereka dalam keseharian.

Perhatian dan telaah terhadap pengajaran bahasa Arab tersebut tetap penting dilakukan sekalipun di pesantren. Sebab kendatipun bahasa Arab sangat identik dengan pesantren, tapi tidak tertutup kemungkinan bahwa pembelajarannya masih memerlukan perbaikan, mengingat bahwa banyak pesantren yang kurang peduli terhadap metode dan kurikulum pembelajaran, padahal keduanya merupakan aspek penting dalam pengembangan pembelajaran.

Berdasarkan pemikiran di atas, maka menarik untuk dilakukan sebuah penelitian tentang pengajaran bahasa Arab pada lembaga pendidikan Islam seperti di pesantren. Oleh karena itu penelitian ini mengambil tema penelitian tentang Pembelajaran Bahasa Arab di Dayah MUDI Mesra Samalanga Kabupaten Bireuen.

Penelitian ini merupakan penelitian bidang kajian evaluasi pendidikan, dengan mengkaji praktek pengajaran bidang studi bahasa Arab yang di Dayah MUDI Mesra Samalangan Kabupaten Bireuen. Berdasarkan sifatnya, penelitian ini tergolong ke dalam penelitian deskriptif. Jika dilihat dari bentuknya, maka penelitian ini dapat dikategorikan kepada penelitian evaluatif. Sedangkan bila dilihat berdasarkan pendekatan filosofis dan disiplin ilmu (terkait dengan data), maka dapatlah ia dimasukkan ke dalam penelitian kualitatif. Adapun dari segi objeknya, kajian ini merupakan kombinasi antara penelitian pustaka (library research) dengan penelitian lapangan (field research). Menurut Mestika Zed, sebuah riset profesional idealnya menggunakan kombinasi antara riset pustaka dan riset lapangan. ${ }^{3}$ Dalam studi Islam, Akhmad Minhaji menyebut penelitian jenis ini sebagai model integrasi, yaitu integrasi antara penelitian pustaka yang berparadigma normatif dengan penelitian lapangan yang berparadigma empiris, yang dinilainya sebagai penelitian ideal bagi studi

3 Mestika Zed, Metode Penelitian Kepustakaan, vol. Cet. I (Jakarta: Yayasan Obor Indonesia, 2004), h. 2. 
Islam. ${ }^{4}$ Data kepustakaan diperoleh melalui teknik dokumentasi, sedangkan data lapangan dikumpulkan melalui teknik wawancara mendalam.

Data primer penelitian ini diambil dari hasil wawancara mendalam dengan para tokoh lembaga pendidikan yang dijadikan subjek penelitian, terutama mereka yang terlibat dengan proses pengajaran bahasa Arab baik dari segi kebijakan maupun praktek di lembaga tersebut. Teknik wawancara mendalam dilakukan dengan wawancara tak berstruktur yang berfokus dengan pertanyaan-pertanyaan yang terbuka, sehingga yang diperlukan adalah interview guide. ${ }^{5}$ Adapun data sekundernya adalah karya-karya yang berbicara tentang pengajaran bahasa asing atau khususnya bahasa Arab, baik berbentuk buku maupun sumber bacaan lain, tidak tertutup kemungkinan artikel-artikel berkaitan yang berasal dari internet secara online maupun bukan.

Melihat data penelitian yang digunakan berasal dari teks (dokumentasi dan hasil wawancara yang ditranskripsikan), maka teknik analisis yang digunakan dalam penelitian ini adalah analisis isi (content analysis), yakni analisis ilmiah tentang isi pesan suatu komunikasi yang tertuang dalam teks atau dokumen. ${ }^{6}$ Data dokumen ataupun wawancara dianalisis kandungan dan isinya, untuk memperoleh suatu kesimpulan yang diambil secara reflektif, yaitu proses mondar-mandir secara cepat antara induksi dan deduksi, antara

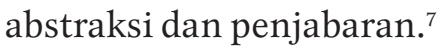

4 Akhmad Minhaji, Strategies for Social Research: The Methodological Imagination in Islamic Studies, vol. Cet. I (Yogyakarta: Suka-Press, 2009), h. 47, 59.

5 Koentjaraningrat, "Metode Wawancara," in Metode-Metode Penelitian Masyarakat, ed. Koentjaraningrat, III, vol. Cet. XIV (Jakarta: Gramedia Pustaka Utama, 1997), h. 138-154.

6 Analisis isi secara teknis mencakup upaya klasifikasi tanda-tanda yang dipakai dalam komunikasi, menggunakan kriteria sebagai dasar klasifikasi, dan menggunakan teknik analisis tertentu sebagai pembuat prediksi. Lihat dalam Noeng Muhadjir, Metodologi Penelitian Kualitatif, III, vol. Cet. VIII, (Yogyakarta: Rake Sarasin, 1998), h. 49.

7 Ibid., h. 6. 


\section{B. Metode Pengajaran Bahasa Arab: Sebuah Definisi Awal}

Dalam sebuah pengajaran, metode merupakan hal yang sangat urgen dan yang harus didahulukan dari pada materi yang akan disampaikan. Sesuai dengan apa yang disebutkan oleh Mahmud Yunus bahwa:

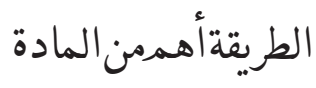

Artinya: "Metode itu lebih penting dari materi/substansi"."

Hal ini disebabkan pengajaran tidak akan tercapai hasil yang memuaskan jika metodenya kurang sesuai. Dengan demikian pengertian metode secara etimologi adalah berasal dari dua perkataan, yaitu meta dan hodos. Meta artinya "melami" dan hodos berarti "jalan" atau "cara". Dalam Kamus Besar Bahasa Indonesia metode berarti "suatu cara yang teratur dan terpikir baik-baik untuk mencapai suatu maksud". ${ }^{10}$ Sedangkan pengertian metode yang penulis maksud adalah suatu sistem atau alat untuk memudahkan pelaksanaan suatu kegiatan guna mencapai suatu tujuan yang telah ditentukan sebelumnya.

Metode Pengajaran Bahasa Arab merupakan suatu usaha meningkatkan kualitas hasil belajar bahasa Arab, karena sukses tidaknya sebuah pengajaran bahasa sering kali dinilai dari segi metode yang digunakan dan karena metodelah yang menentukan bahwa metode itu tidak penting digunakan, yang penting adalah kemauan belajar dan kualitas murid. Disamping itu juga ada yang berpendapat bahwa metode hanyalah sekedar alat saja akan tetapi gurulah yang paling menentukan berhasil atau tidaknya suatu pengajaran, maka berdasarkan hal tersebut agar tidak terjadinya pemahaman yang beragam dalam memahami tulisan ini penulis merasa perlu menjelaskan tentang pengertian metode pengajaran bahasa Arab itu sendiri.

Sebelum lebih jauh menerangkan tentang pengembangan metode bahasa Arab, terlebih dahulu akan dikemukakan pentingnya penamaan metode.

\footnotetext{
8 Mahmud Yunus, At-Tarbiyah Wa at-Ta'lim (Gontor: Darussalam Press, 1994), h. 14.

9 M. Arifin, Ilmu Pendidikan Islam, (Jakarta: Bumi Aksara, 2000), h. 61.

${ }^{10}$ Tim Penyusun, Kamus Besar Bahasa Indonesia, (Jakarta: Balai Pustaka, 1994), h. 215.
} 
Artikel yang disajikan oleh Edward M. Anthony dengan judul "Approach, Metheod, and Technique", dengan maksud mengusahakan agar lapangan pengajaran bahasa mencapai taraf ilmiah ketimbang hanya mengambang pada taraf eksperimental dan empiris ternyata banyak mengundang perhatian para pakar pengajaran bahasa. Pernyataan berikut ini ditulis oleh Anthony pada majalah English Language Teaching, seperti yang dikutip oleh Azhar Arsyad sebagai berikut:

..., I view an approach-any approach-as a set of correlative assumption dealing with the nature of language teaching and learning. An approach is axiomatic....Method is an overall plan for the orderly presentation of language material, no part of which contradicts, and all of which is based upon the selected approach... A method isprocedural. A technique is implementation that which takes place in a classroom. ${ }^{11}$

Approach/pendekatan yang dalam bahasa Arab disebut "al-madkhal" adalah seperangkat asumsi mengenai hakikat bahasa dan hakikat belajarmengajar bahasa. Sifatnya aksiomatik (filosofis). Sedangkan metode dalam bahasa Arab disebut "al-Thariqah" adalah rencana menyeluruh yang berkenaan dengan penyajian materi bahasa secara teratur, tidak ada satu bagian yang bertentangan dengan yang lain dan semuanya berdasarkan atas approach yang telah dipilih. Sifatnya prosedural. Teknik atau "al-uslub" yaitu apa yang sesungguhnya terjadi di dalam kelas dan merupakan pelaksanaan dari metode, sifatnya implementatif. ${ }^{2}$

Secara umum, metode pengajaran bahasa Arab dapat digolongkan menjadi dua yaitu metode tradisional dan modern. Metode tradisional berarti belajar secara mendalam tentang seluk-beluk bahasa Arab yaitu nahwu dan sharaf. Sedangkan metode modern adalah belajar bahasa Arab supaya mampu untuk menggunakan bahasa tersebut secara aktif dan mampu memahami ungkapan

${ }^{11}$ Azhar Arsyad, Bahasa Arab Dan Metode Pengajarannya, (Yogyakarta: Pustaka Pelajar, 2003), h. 19.

${ }^{12}$ Ibid., h. 25. 
dalam bahasa Arab. Namun, dalam kajian ini yang dijadikan landasan analisis adalah pandangan yang lebih luas tentang metode pengajaran bahasa, yakni:

a. Metode Tarjamah (Translation); Pengajaran huruf-huruf abjad dengan metode yang tradisional, kemudian mengajarkan menulis dan membaca, kemudian murid menghafalkan kata-kata atau mufradat dengan artinya dalam bahasanya sendiri. Latihan umumnya dengan terjemah, metode seperti ini amat gersang dan membtuhkan waktu yang cukup lama. Hasilnya ternyata belum dapat mengucapkan dengan baik atau mengekspresikan pikiran dan perasaan secara lisan dan tulisan.

b. Metode Qawaid (Grammar); Metode Qawaid (Grammar) yaitu pengajaran bahasa Arab dengan permulaan menghafal aturan-aturan tata bahasa (rule of grammar), seperti pembelajaran ilmu nahwu dan sharaf serta ilmu tata bahasa lainnya.

c. Metode Langsung (Thariqah al-Mubasyirah/Direct Method); Tekniknya adalah dengan membuat suatu wilayah lingkungan Bahasa dan tidak menggunakan bahasa murid atau Bahasa perantara, tetapi mengemukakan gerak, gambar, dan alat-alat peraga yang bermacammacam untuk mengasosiasikan lafaz dengan arti, mengajarkan Bahasa arab dengan metode ini tidak menggunakan Bahasa Indonesia atau Bahasa Inggris sama sekali tapi hanya menggunakan Bahasa Arab semata-mata sampai murid mengetahui maksudnya. Munculnya metode langsung ini di pesantren didasari pada asumsi bahwa bahasa adalah sesuatu yang hidup, oleh karena itu harus dikomunikasikan dan dilatih terus sebagaimana anak kecil belajar bahasa ibu. Metode ini dikembangkan karena ketidakpuasan sebagian pihak pengelola pesantren dalam pengajaran bahasa Arab secara tradisional di banyak pesantren di Indonesia, dimana para peserta didik selama bertahuntahun belajar tata bahasa dan ilmu kebahasaan lainnya dipesantren, tapi mereka tidak pandai berbicara, mengarang dan menulis bahasa Arab. Hal ini bukan disebabkan karena ketidakmampuan peserta didik 
dalam belajar, melainkan karena metode yang menekankan materi ilmu kebahasaan secara rumit tanpa didukung oleh ketrampilan mempergunakannya.

d. Metode Qawaid dan Tarjamah (Grammar and Translation). Metode ini adalah kombinasi antara metode gramatika (qawaid) dan metode tarjamah (translation), yaitu pengajaran bahasa Arab dengan permulaan menghafal aturan-aturan tata bahasa (rule of grammar), seperti pembelajaran ilmu nahwu dan sharaf serta ilmu tata bahasa lainnya, kemudian pada tahap pembelajaran selanjutnya. menyusun daftar kata dan, mengurai fungsi-fungsi kata dalam kalimat tersebut ('irab) lalu menerjemahkan kalimat demi kalimat yang terdapat dalam bahagiannya sesuai maksud tata bahasa dan i'rab-nya.

Sementara itu, makna dari pengajaran adalah suatu kegiatan yang dilakukan oleh seorang guru dalam menyampaikan pengetahuan kepada siswa". ${ }^{13}$ Pengajaran yang berlangsung sebagai suatu proses yang saling mempengaruhi antara guru dan siswa, dimana antara keduanya terdapat hubungan atau komunikasi interaksi yaitu guru mengajarkan disatu pihak dan murid belajar dilain pihak.

Proses pengajaran berlangsung dalam situasi pengajaran yang dalamnya terdapat beberapa unsur dan komponen, yaitu: (a) Tujuan mengajar; (b) Siswa yang belajar; (c) Guru yang mengajar; (d) Metode mengajar; (e) Alat Bantu mengajar/media; dan (f) Situasi pengajaran. ${ }^{14}$

Dalam proses pengajaran, seluruh komponen tersebut bergerak secara sekaligus dalam suatu rangkaian yang terarah. Maka dengan demikian pengajaran berartijuga suatu pola dimana didalamnya tersusun suatu prosedur yang terencana.

Pengajaran merupakan profesi yang membutuhkan pengetahuan, keterampilan, dan kecermatan karena ia sama halnya dengan pelatihan

\footnotetext{
${ }^{13}$ Oemar Hamalik, Proses Belajar Mengajar, (Jakarta: Bumi Aksara, 2006), h. 54.

${ }^{14}$ Ibid., h. 55.
} 
kecakapan yang memerlukan kiat, strategi dan ketelatenan, sehingga menjadi cakap dan professional. Penerapan metode pengajaran tidak akan berjalan dengan efektif dan efisien sebagai media pengantar materi pengajaran bila penerapannya tanpa didasari dengan pengetahuan yang memadai tentang metode itu. Sehingga metode bisa saja akan menjadi penghambat jalannya proses pengajaran, bukan komponen yang menunjang pencapaian tujuan, jika tidak tepat aplikasinya. Oleh karena itu, penting sekali untuk memahami dengan baik dan benar tentang karakteristik suatu metode.

Sedangkan Bahasa Arabitu sendiri terdiri dari dua suku kata, yaitu "bahasa" dan "Arab". Secara etimologi memiliki pengertian masing-masing sebelum tergabung menjadi sebuah struktur kata. Bahasa merupakan "alat yang terdiri dari satuan bunyi-bunyi berartikulasi yang dipakai untuk berhubungan baik secara tertulis maupun secara lisan". ${ }^{15}$ Bahasa atau "لغذ"/Lughatun" dalam bahasa arabnya seperti disebutkan Ibnu Jinni dalam al-Khashais:

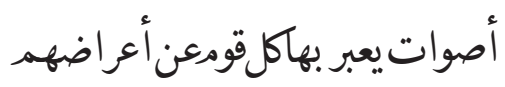

"Suara yang digunakan oleh suatu kelompok/bangsa untuk mengungkapkan/mengekspresikan maksud dan tujuan mereka".16

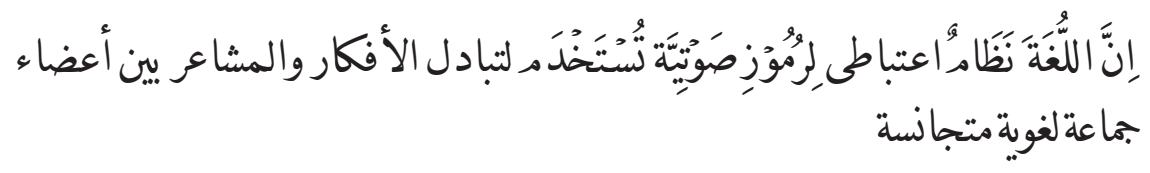

"Bahasa dalam sistem lambang bunyi yang arbiter, digunakan untuk saling bertukar fikiran dan perasaan antar anggota kelompok masyarakat bahasa".17

Saussure memberikan defenisi bahasa ialah, "Language is a mental system that forms a bond or rules on language elements both at the level of phonology,

\footnotetext{
${ }^{15}$ Penyusun, Kamus Besar Bahasa Indonesia, h. 120.

${ }^{16}$ Abu al-Fath Utsman Ibnu Jinni, Al-Khashais, ed. Muhammad Ali al-Najjar (Bairut: Alam al-Kutub, 1983), h. 89.

${ }^{17}$ Amin al-Khulli, Manahij at-Tajdid Fi an-Nahwu Wa Al-Balaghah Wa at-Tafsir Wa Al-Adab, (Cairo: Dar al-Ma'rifat, 1961), h. 5.
} 
morphology, and syntax, yang maksudnya "Bahasa adalah sistem mental yang membentuk suatu ikatan atau aturan pada unsur-unsur bahasa baik pada tataran fonologi, morfologi, maupun sintaksis". ${ }^{18}$

Menurut beberapa pemahaman di atas dapat didefenisikan kembali tentang arti bahasa, adalah sistem lambang bunyi yang arbitrer, yang dipergunakan oleh sebuah komunitas masyarakat atau bangsa sebagai sarana untuk berkomunikasi, memindahkan dan mengungkapkan suatu fikiran, pengertian, perasaan dan keinginan seseorang. Ibaratnya bahasa seperti kaca cermin yang daripadanya fikiran memantul.

Sedangkan menyangkut dengan istilah bahasa Arab para ahli bahasa Arab terlebih dahulu mengelompokkan bahasa-bahasa di dunia dalam beberapa rumpun. Ali Abdul Hahid Wafiy menyebutkan, bahasa terbagi kepada tiga rumpun yaitu Indo Eropa, Homo Semetic dan Turania..$^{19}$ Bahasa Arab tergolong kedalam Homo Semetic (bahasa Semit). Bahasa Semit pada garis besarnya dibagi kepada dua golongan besar, yaitu bahasa Semit bagian utara yang didalamnya mencakup bahasa al-Akkadiyah (Accadian), al-Kan'aniyah (Cannanic) dan alAramiyah (Aramaeic). Bahasa Arab (Arabic, al-'Arabiyah) adalah bahasa Semit bagian selatan yang di dalamnya juga termasuk bahasa Ethiopia (Ethiopic, alHabasyah).

Imil Badi' Ya'qub membagi bahasa Semit menjadi bahasa Semit Timur dan bahasa Semit Barat. Bahasa Semit Timur meliputi bahasa Syiria (al-Asywariah), Babilonia (al-Babilah, Babilion) dan Akadiyah (al-Akkadiyah, Accadian). Sedangkan bahasa Semit Barat meliputi bahasa Kan'an (al-Kan'aniyah, Kananic) dan bahasa Arab (al-'Arabiyah, Arabic). Lebih lanjut menurut Imil Badi' Ya'qub menjelaskan, bahasa Arab selatan yang mencakup bahasa Mi'ain (al-Mi'aniyah, Minoan), Sabai (as-Sababiyah, Sabean) Hadhramaut, Qathban (al-Qathbaniyah, Qathbanic) dan Habsyi (al-Habsyiah, Ethiopic). Adapun

${ }^{18}$ Ferdinand De Saussure, Course in General Linguistics, (London: bloomsbury Academic, 2013), h. 25.

${ }^{19}$ Ali Abdul Wahid Wafy, Ilmu Al-Lughah, (Kairo: Maktabah an-Nahdhah Misr bi alFajalah, 1962), h. 165. 
bahasa Arab Utara mencakup bahasa al-Baidah dan al-Baqiyah. Bahasa Arab al-Baqiyah adalah bahasa yang dipakai di wilayah Tamim dan Hijaz, ${ }^{20}$ dan merupakan bahasa Arab yang berkembang sampai kepada zaman kita sekarang dan dipakai secara resmi. ${ }^{21}$

\section{Pembelajaran Bahasa Arab Pada Dayah MUDI Mesra}

\section{Sejarah Pendirian dan Kepemimpinan}

Dayah Ma'hadal 'Ulum Diniyah Islamiyah (MUDI) berlokasi di Desa Mideuen Jok Kemukiman Mesjid Raya, Kecamatan Samalanga, Kabupaten Bireuen Propinsi Aceh. Dayah MUDI ini didirikan seiring dengan pembangunan Mesjid Raya yang peletakan batu pertamanya dilakukan oleh Sultan Iskandar Muda (1607-1636). Pimpinan Dayah MUDI yang pertama adalah Faqih Abdul Ghani. Namun tidak tercatat dalam sejarah sampai tahun berapa beliau memimpin lembaga pendidikan Islam ini dan siapa penggantinya kemudian. ${ }^{22}$

Pada tahun 1927, barulah dijumpai secara jelas catatan sejarah yang meriwayatkan perjalanan pimpinan dayah tersebut. Dari tahun ini, Dayah MUDI dipimpin oleh Teungku Haji Syihabuddin bin Idris dengan para santri masa itu berjumlah 100 orang putra dan 50 orang putri. Mereka diasuh oleh 5 orang tenaga pengajar lelaki dan 2 orang guru putri. Sesuai dengan kondisi zaman pada masa itu, bangunan asrama tempat menampung para santri merupakan barak-barak darurat yang dibangun dari batang bambu dan rumbia. ${ }^{23}$

${ }^{20}$ Imil Badi’ Ya'qub, Figh Al-Lughah Al-Arabiyah Wa Khashaishuha, (Beirut: Dar alTsaqafah al-Islamiyah, 1982), h. 114-115.

${ }^{21}$ Ibid.

${ }^{22}$ Tim Penulis Dayah MUDI, Profil Dayah MUDI Mesra Samalanga, cet. II (Bireuen: t.p., 2012), h. 3.

${ }^{23}$ Teungku Mukhlisuddin, Kepala Sekretariat Dayah MUDI Mesra Samalanga, Wawancara, November 5, 2016. 
Tahun 1989, pergantian kepemimpinan dayah diperoleh berdasarkan hasil kesepakatan para alumni dan masyarakat. Melalui berbagai pertimbangan, musyawarah alumni tersebut mempercayakan kepemimpinan Dayah MUDI kepada salah seorang menantunya yaitu Teungku Haji Hasanoel Bashri bin Haji Gadeng. Teungku Haji Hasanoel Bashri yang sekarang lebih dikenal dengan sapaan Abu MUDI adalah murid senior lulusan dayah itu sendiri yang sudah berpengalaman mengelola kepemimpinan dayah semasa Teungku Haji Abdul 'Aziz mulai jatuh sakit. ${ }^{24}$

Di masa kepemimpinan Abu MUDI, dayah mengalami kemajuan pesat. Jumlah pelajar yang menuntut ilmu pada dayah tesebut semakin bertambah dari waktu ke waktu. Para pelajar ini datang dari berbagai daerah baik dari dalam maupun luar Provinsi Aceh, sampai saat ini jumlah santri mencapai 5000 (lima ribu) orang. Berikut adalah tabel nama-nama pimpinan Dayah MUDI Samalanga dari masa ke masa:

Tabel I. Pimpinan Dayah MUDI dari Masa ke Masa

\begin{tabular}{|c|l|l|l|}
\hline No & \multicolumn{1}{|c|}{ Nama } & \multicolumn{1}{|c|}{ Tahun } & Ket \\
\hline 1 & Teungku Faqeh Abdul Ghani & - & \\
2 & Teungku H. Syihabuddin Bin Idris & $1927-1935$ & \\
3 & Teungku H. Hanafiah Bin Abbas & $1935-1964$ & \\
4 & Teungku H. Abdul Aziz Bin M. Shaleh & $1964-1989$ & \\
5 & Teungku H. Hasanoel Bashry Bin H.G & 1989 -sekarang & \\
\hline
\end{tabular}

Sumber data: Sekretariat Dayah MUDI

\section{2. "Mabna Lughah" Sebagai Unit Pembelajaran Bahasa Arab Modern}

Dayah Ma'hadal Ulum Diniyah Islamiyah (MUDI) Mesjid Raya (MESRA) merupakan sebuah Lembaga Pendidikan yang telah menelurkan beribu-ribu alumni yang dapat membimbing masyarakat Aceh secara khusus dan dunia secara umum. Seiring dengan perkembangan zaman,

${ }^{24}$ Ibid. 
kita dituntut untuk menyesuaikan diri dengan masa kita, maka berdasarkan intruksi dari pimpinan Dayah MUDI Mesra Samalanga, bahasa Arab menjadi mata pelajaran baru di dayah tersebut.

Langkah pertama yang ditempuh untuk pengembangan bahasa Arab adalah mendidik kader guru bahasa Arab. Program ini direalisasi dengan mendidik Santri-santri berprestasi dan alumnus pesantren modern dengan tutor Ridwan Syahabuddin dan Ziadi. ${ }^{25}$ Pada tahun 2001 dibentuklah pengurus bahasa Arab yang diketuai oleh Ridwan Syahabuddin. Pada tahun ini tujuan program bahasa masih menindak lanjuti tujuan dari langkah pertama, yaitu mendidik kader guru bahasa namun sistem pengajarannya dirubah dari mendidik Santri berprestasi dan alumnus pesantren modern dengan mendidik satri kelas $\mathrm{V}$ pada setiap hari senin.

Staf Pengajar pada fase ini adalah santri angkatan pertama dari Mabna Lughah yang masih aktif di Dayah MUDI Mesra. Hasil yang dicapai pada tahapan kedua ini walaupun belum begitu memuaskan, karena dalam percakapan sehari-hari para santri masih menggunakan bahasa daerah, namun animo santri untuk mengikuti bergabung ke Mabna Lughah semakin bertambah.

Untuk mengokohkan bahasa Arab di Dayah MUDI Mesra, Pimpinan dayah Syekh Hasanoel Bashri mengintruksikan agar dibentuk sebuah asrama khusus untuk santri yang dididik sebagai kader guru bahasa Arab. Maka pada tahun 2003 terbentuklah Mabna Lughah atas kerja sama dan dukungan dewan guru Dayah MUDI Mesra sebagai realisasi instruksi pimpinan. Sistem dan manajemennya juga berubah. Ridwan Syahabuddin bertindak sebagai ketua umum dan Muslim M. Saleh sebagai ketua pelaksana. Setahun kemudian Ridwan Syahabuddin yang menjadi ikon

${ }^{25}$ Ridwan Syahabuddin dan Ziadi adalah alumnus Pondok Modern Darussalam Gontor Ponorogo asal Aceh. Setelah menamatkan pendidikan di Gontor tahun 1996, keduanya kembali ke Dayah MUDI Mesra Samalanga Kabupaten Bireuen dan menjadi perintis Mabna Lughah di Dayah tersebut., Data didapatkan dari sekretariat Dayah MUDI dan hasil wawancara tanggal 05 November 2016 via telepon seluler dengan Ridwan Syahabuddin yang sekarang menetap di Medan Sumatera Utara menjadi salah satu pimpinan pesantren disana. 
dan perintis pembelajaran bahasa di Dayah MUDI berangkat ke Yaman untuk menempuh pendidikan Strata 2, maka Mabna Lughah Dayah MUDI sejak saat itu diketuai oleh Muslim M. Saleh.

Setelah terbentuknya Mabna Lughah, bahasa Arab di Dayah MUDI Mesra sudah bukan lagi suatu hal yang tabu. Ini dapat dilihat dari percakapan sehari-hari anggota Mabna Lughah yang menggunakan bahasa Arab dan juga berjalannya berbagai i'lan (pengumuman) dengan berbahasa Arab.

Pada tahun 2005 bahasa Arab mulai dibentuk di komplek santriwati. Adalah Siti Zulaikha Ibrahim yang mengabdikan dirinya untuk mengembangkan bahasa Arab di komplek putri. Untuk membantu berjalannya pengembangan bahasa Arab di komplek putri juga dibantu oleh santriwati alumnus Pesantren Modern di provinsi Aceh.

Visi dan misi dari Mabna Lughah Dayah MUDI Mesra Samalanga adalah memantapkan pandangan masyarakat terhadap pesantren salafiah serta menumbuhkan kepercayaan diri dalam diri santri Dayah MUDI Mesra ketika bergaul dengan santri pesantren 'ashry, karena sebelumnya terdapat kesan bahwa pesantren salafiah mulai redup seiring berkembangnya pesantren modern yang lebih maju dan dapat mengikuti perkembangan zaman. $^{26}$

\section{Faktor-faktor yang Mendukung Terbentuknya Lingkungan Berbahasa Arab}

Faktor yang paling penting dalam akselerasi penguasaan suatu bahasa adalah al-ta'arrudl al-lughawi, yaitu, seorang pembelajar menerjunkan dirinya ke dalam lingkungan pengguna bahasa yang sedang dia pelajari. Di ibaratkan al-ta'arrudh al-lughawi dapat diartikan sebagai al-ta'arrudl li al-syams, atau siapa yang menginginkan dapat sinar matahari, maka hendaknya dia keluar ruangan dan berada langsung di bawah sinar matahari. Dan yang dimaksud dengan al-ta'arrudl al-lughawi adalah seorang

${ }^{26}$ Dokumentasi Mabna Lughah Dayah MUDI Mesra Samalanga, 2016. 
pembelajar bahasa harus berada pada lingkungan bahasa yang sedang dia pelajari. Lingkungan bahasa dalam hal ini bahasa Arab ada dua macam. Yaitu; 1) Lingkungan Asli, dan 2) Lingkungan Buatan.

Sebagai perbandingan, siapa yang berada pada lingkungan bahasa yang sedang dia pelajari, ia dapat diibaratkan berada dalam posisi bagaikan 50 (lima puluh) guru mengajari 1 (satu) murid yang sudah pasti akan sangat efisien dan efektif dalam akselerasi belajar bahasa yang sedang dia pelajari, sedangkan yang belajar dikelas dan tidak berada di asrama atau lingkungan bahasa yang sedang dipelajari hanyalah satu orang guru yang mengajari 30 (tiga puluh) atau 40 (empat puluh) murid yang tentu saja tidak bisa dibandingkan efesiensi dan efektifitasnya dengan yang pertama. ${ }^{27}$

Mabna Lughah Dayah MUDI Mesra adalah sebuah sebutan untuk asrama yang menjadi tempat berdomisili bagi santri yang mempelajari bahasa Arab di Dayah MUDI Mesra Samalanga. Mabna Lughah termasuk dalam kategori Bi'ah Arabiyah yang berarti lingkungan berbahasa Arab. Dalam pendidikan formal, atmosfer berbahasa Arab dapat diciptakan oleh guru di lokasi sekolah atau di asrama khusus bagi pelajar yang biasa dikenal dengan boarding school.

Pengertian asrama menurut Pemerintah adalah bangunan sederhana yang dibangun dan dibiayai oleh universitas, sekolah atau kampus tertentu, perorangan atau pemerintah daerah yang diperuntukkan khusus untuk pemondokan pelajar atau mahasiwa, dapat berupa bangunan gedung bertingkat atau tidak. Di dalam asrama para siswa dapat merasakan keramahan para pengasuhnya yang mengajar mereka secara sabar dan telaten dan dari sikap pengasuh yang demikian, lalu diikuti dan diteladani oleh para penghuni asrama lainnya sehingga keberlangsungan kegiatan pembelajaran menjadi semakin kondusif, maka pembelajaran bahasa akan semakin sukses.

${ }^{27}$ Moeliomo A.M., Pengembangan Dan Pembinaan Bahasa, (Jakarta: Gramedia, 1985), h. 27. 
Adapun tujuan diadakannya asrama adalah: (1) Memberi kemudahan tempat tinggal kepada pelajar yang jauh dari kawasan dan tidak berkemampuan dari segi keuangan, (2) Menjaga keselamatan pelajar dari masalah sosial, (3) Melatih pelajar mendisiplinkan diri baik dari segi mental maupun fisik serta menyemaikan sikap berdikari dan bertolak ansur, dan (4) Asrama memberikan kesempatan yang baik untuk pengenalan aktifitas ketrampilan hidup.

Penempatan santri dalam asrama bahasa, sebenarnya sangat mirip dengan apa yang disebut dengan program homestay yang akhir-akhir ini banyak dijadikan model untuk mempelajari bahasa kedua yang biasanya diambil pada masa liburan. Program homestay yang ditawarkan adalah belajar bahasa Inggris langsung ke negara-negara pemakai bahasa itu sendiri, misalnya ke negara Amerika Serikat, Australia, Inggris, Selandia Baru dan Singapura yang mana manfaatnya para pelajar akan memperoleh pengalaman berskala internasional dan mengalami pergaulan antara bangsa. Melalui homestay para pelajar akan tinggal indekos di salah satu keluarga yang merupakan native speaker (pembicara asli bahasa Inggris).

Homestay merupakan pilihan akomodasi yang populer di Australia, terutama untuk siswa-siswa yang mengikuti kursus bahasa Inggris. Tinggal dengan hostfamily (keluarga yang menampung) membuka banyak kesempatan berharga untuk melakukan percakapan dengan mereka dalam suatu lingkungan berbahasa Inggris. Para siswa dapat belajar lebih cepat karena mereka terus berpikir dan berbicara menggunakan bahasa Inggris dalam situasi-situasi yang amat praktis. Di negara-negara maju, keberadaan homestay menjadi sebuah kebutuhan dan dikategorikan sebagai media pembelajaran efektif yang dinilai dapat mempercepat pemerolehan bahasa bagi pelajar asing. ${ }^{28}$

Lingkungan Umum di Dayah MUDI Mesra bukanlah lingkungan bahasa yang menyeluruh seperti halnya lingkungan bahasa yang ada dipondok

${ }^{28}$ Ibid., h. 30 . 
modern di Indonesia pada umumnya, yang mewajibkan seluruh entitas santri untuk menggunakan bahasa Arab atau Inggris untuk berkomunikasi dalam seluruh aktifitas mereka (kalamil yaumiyah/dayly speak). Seperti yang telah penulis ungkapkan sebelumnya, sejak tahun 2001 pada awal berdirinya Mabna Lughah adalah sebagai unit pengelola bahasa Asing di Dayah MUDI dengan sasaran mengasramakan secara khusus santrisantri kelas V di Dayah MUDI atau santri-santri alumni pesantren modern yang nyantri kembali di Dayah MUDI, atau santri-santri berprestasi secara terpisah dari lingkungan asrama santri Dayah MUDI. Disamping itu, para santri yang yang sudah tergabung di dalam Mabna Lughah juga harus mengikuti kurikulum dayah tradisional sebagaimana ketentuan dan aturan bagi seluruh di Dayah MUDI, artinya mereka dituntut untuk bisa menyesuaikan diri dengan dua lingkungan pembelajaran. Namun jika dilihat dari skala kecil, usaha pembentukan Mabna Lughah yang digagas oleh Pimpinan Dayah telah terlaksana walaupun lingkupnya masih kecil, dengan harapan dapat terus berkembang.

\section{Upaya Mabna Lughah Dalam Pembelajaran Bahasa Arab}

Upaya mabna lughah Dayah MUDI dalam pembelajaran bahasa Arab meliputi beberapa hal, diantaranya:

a) Membagikan pelajaran bahasa Arab dalam 2 katagori, yaitu: (1) Pemberian mufradat dan kalimat; (2) Praktek percakapan seharihari

b) Jadwal pelaksanaan pengajaran bahasa Arab, yaitu: (1) Mufradat diberikan setiap pagi selain hari jum'at; (2) Setiap siang senin dan kamis dilaksanakan muhadatsah di teras Mabna Lughah; (3) Hari jum'at pagi diadakan muhadatsah/percakapan secara bersama di depan STAI Al-aziziyah

c) Waktu pengajaran bahasa Arab, yaitu: Pagi selain pagi jum'at, Pukul 05.45-06.00 WIB, santri mulai mengikuti pembacaan mufradat sampai selesai. Pagi jum'at, pukul 06.00-07.00 WIB, 
santri mengikuti muhadatsah di depan STAI Al-Aziziyah. Siang selain siang senin, kamis dan jum'at, Pukul 13.15-13.30 WIB, santri mulai mengikuti pengulangan mufradat sampai selesai. Siang senin dan kamis, Pukul 13.15-13.30 WIB, santri mulai mengikuti muhadatsah/percakapan.

d) Persiapan dan pemberian mufradat dalam pengajaran bahasa Arab, yaitu: (1) Mufradat dan kalimatnya disediakan di papan tulis oleh mudabbir yang ditugaskan; (2) Santri wajib memiliki 3 buku tulis lux, yaitu: 1 Buku tulis untuk mufradat ismiyah; 1 Buku tulis untuk mufradat fi'liyah; 1 Buku catatan kecil/buku saku; (3) Mufradat dicatat dan dibacakan oleh ketua tiap-tiap kamar atau yang di tugaskan; (4) Mufradat dibacakan secara serentak oleh anggota kamar.

e) Persiapan muhadatsah dan pelaksaaannya, yaitu: (1) Jadwal pelaksanaan muhadatsah adalah jadwal yang telah ditentukan di atas; (2) Muhadatsah dilakukan di depan STAI Al-Aziziyah atau di teras mabna lughah; (3) Barisan muhadatsah diatur oleh ketua kamar; (4) Setiap santri wajib memiliki buku percakapan sehari-hari; (5) Muhadatsah dipimpin oleh mudabbir; (6) Materi muhadatsah ditentukan oleh mudabbir (7) Materi disusun dalam bentuk jadwal dan ditempelkan

f) Pengawasan; (1) Setiap kamar dikomandoi oleh 2 orang mudabbir; (2) Mudabbir yang telah dipercayakan wajib mengawasi setiap anggota kamarnya; (3) Mudabbiryang berhalangan wajib melapor kepada Qismu al-Tarbiyah; (4) Mudabbir harus menguasai materi yang akan diberikan; (5) Mengarahkan dan membimbing anggota kamar; (6) Harus disiplin dan teliti dalam menjaga waktu bertugas.

g) Peraturan Mabna Lughah

Mabna Lughah pada dasarnya memiliki peraturan tersendiri yang mendukung pelaksanaan peraturan Dayah MUDI secara optimal. Ketika 
bahasa menjadi hal penting bagi santri di Mabna Lughah Dayah MUDI, bukan berarti Mabna Lughah meninggalkan peraturan dan ketentuan umum yang telah diterapkan di Dayah MUDI, bahkan dengan tidak mengurangi ruh dan tujuan serta fungsi dari peraturan Dayah MUDI sendiri Mabna Lughah meningkatkan realisasi peraturan di kalangan santri, walau peraturan yang diadopsi hanya sebatas peraturan yang berlaku di asrama karena wewenang Mabna Lughah yang terbatas.

Pembelajaran bahasa Arab di Mabna Lughah Dayah MUDI Samalanga sudah bisa dikatakan efektif. Hal ini dapat dilihat bahwa sebagian besar santri yang berdomisili di Mabna Lughah Dayah MUDI Samalanga sudah bisa memahami bahasa Arab dalam kehidupan sehari-hari, santri mudah menghafal sebagian text kitab kuning, dan santri mulai bersemangat atau motivasi dalam belajar bahasa Arab, apalagi kedepannya akan diadakan debat berbahasa Arab.

Kadangkala Sukarnya mempelajari bahasa Arab berkaitan dengan metode pembelajaran. Tidak perlu heran karena metode pada awalnya tidak terlalu penting. Baru saja dirasakan pentingnya ketika terjadi peristiwa yang merusak citra bahasa Arab. Terdapat beberapa hal yang mesti lebih diperhatikan dalam pembelajaran bahasa Arab:

1) Titik tolak perhatian ada pada bahasa Arab fusha.

2) Pengajaran dengan sebanyak-banyaknya memperaktekkan ucapan dan susunan bahasa yang baku berulang-ulang.

3) Memakai buku pelajaran yang sesuai dengan lingkungan pembelajaran bahasa Arab.

4) Memilih kosa kata yang banyak berkembang dan selalu dibutuhkan dalam jumlah total 3000 kata; 1000 untuk tingkat permulaan, 2000 untuk tingkat lanjutan dan penyajiannya dalam bentuk tersusun dalam kalimat.

5) Menyisihkan waktu untuk menulis baik dalam bentuk insyak maupun latihan-latihan.

6) Mengupayakan buku pegangan untuk guru. 


\section{Kesimpulan}

Mabna Lughah merupakan tempat berdomisili bagi santri yang mempelajari bahasa Arab di Dayah MUDI Mesra Samalanga. Mabna Lughah termasuk dalam kategori Bi'ah Arabiyah yang berarti lingkungan berbahasa Arab. Dalam pendidikan formal, atmosfer berbahasa Arab dapat diciptakan oleh guru di lokasi sekolah atau di asrama khusus bagi pelajar yang biasa dikenal dengan boarding school. Upaya yang dilakukan Mabna Lughah dalam mengefektifkan bahasa Arab sudah sangat baik yaitu dengan menempatkan santri dalam satu asrama sehingga membawa suasana seakan santri barada dalam linkungan bahasa Arab yang asli.

Hal ini pula memudahkan pendidik untuk lebih mengenal peserta didik secara kejiwaan maupun kemampuan. Faktor yang mendukung terbentuknya lingkungan berbahasa Arab (Bi'ah al-Lughah al-'Arabiyah) di Mabna Lughah Dayah MUDI Mesra Samalanga jelas mumpuni dengan adanya kurikulum serta tenaga pendidik yang hebat, walaupun disebagian tempat kurang terealisasi sebagaimana semestinya, seperti Laboratorium bahasa serta Listening berbahasa Arab bagi santri. Kurang mendukungnya faktor laboratorium serta listening bisa menimbulakan kendala yang berkelanjutan bagi Mabna Lughah. Akan sangat baik untuk meningkatkan kualitas bahasa Arab santri Dayah MUDI mesra sekiranya pembelajaran bahasa Arab dapat berjalan dengan dukungan Laboratorium bahasa.[]

\section{Daftar Pustaka}

Abu al-Fath Utsman Ibnu Jinni, al-Khashais, Muhammad Ali al-Najjar. ed, Bairut: Alam al-Kutub. 1983.

Amin al-Khulli, Manahij at-Tajdid fi an-Nahwu wa al-Balaghah wa at-Tafsir wa al-Adab, Cairo: Dar al-Ma'rifat: 1961.

Azhar Arsyad, Bahasa Arab dan Metode Pengajarannya, Yogyakarta: Pustaka Pelajar, 2003. 
Ali Abdul Wahid Wafy, Ilmu al-Lughah, Cairo: Maktabah an-Nahdhah Misr bi al-Fajalah, 1962.

Akhmad Minhaji, Strategies for Social Research: the Methodological Imagination in Islamic Studies, Cet. I, Yogyakarta: Suka-Press, 2009.

Radliyah Zaenuddin, dkk, Metodologi dan Strategi Alternatif Pembelajaran Bahasa Arab, Yogyakarta: Pustaka Rihlah Group, 2005.

Thayar Yusuf dan Syaiful Anwar, Metode Pengajaran Agama dan Bahasa Arab, Jakarta: Raja Grafindo Persada, 1994.

Mestika Zed, Metode Penelitian Kepustakaan, Cet. I, Jakarta: Yayasan Obor Indonesia, 2004.

Koentjaraningrat (ed.), Metode-Metode Penelitian Masyarakat. Cet. XIV, Edisi III, Jakarta: Gramedia Pustaka Utama, 1997.

Noeng Muhadjir, Metodologi Penelitian Kualitatif, Cet. VIII, Edisi III; Yogyakarta: Rake Sarasin, 1998.

Mahmud Yunus \& Muhammad Qasim Bakri, at-Tarbiyah wa at-Ta'lim, Gontor: Darussalam Press, 1994.

M. Arifin, Ilmu Pendidikan Islam, Jakarta: Bumi Aksara, 2000.

Tim Penyusun, Kamus Besar Bahasa Indonesia, Jakarta: Balai Pustaka, 1994.

Oemar Hamalik, Proses Belajar Mengajar, Jakarta: Bumi Aksara, 2006.

Ferdinand De Saussure, Course in General Linguistics, London: bloomsbury Academic, 2013.

Imil Badi' Ya'qub, Figh al-Lughah al-Arabiyah wa Khashaishuha, Beirut: Dar al-Tsaqafah al-Islamiyah, 1982.

Tim Penulis Dayah MUDI, Profil Dayah MUDI Mesra Samalanga, Bireuen: t.p., 2012.

Moeliomo, A.M. Pengembangan dan Pembinaan Bahasa, Jakarta: Gramedia, 1985. 